\title{
ClpP regulates breast cancer cell proliferation, invasion and apoptosis by modulating the Src/PI3K/Akt signaling pathway
}

\author{
Juan Luo $^{1}$, Beilei Zeng ${ }^{1}$, Chunfang Tao ${ }^{1}$, Mengqi Lu ${ }^{1}$, Tingxiu Xiang ${ }^{1}$, Guosheng Ren $^{\text {Corresp. } 1,2}$ \\ ${ }^{1}$ Chongqing Key Laboratory of Molecular Oncology and Epigenetics, The First Affiliated Hospital of Chongqing Medical University, Chongqing, China \\ 2 Department of Endocrine and Breast Surgery, The First Affiliated Hospital of Chongqing Medical University, Chongqing, China \\ Corresponding Author: Guosheng Ren \\ Email address: rengs726@126.com
}

Background. Caseinolytic protease $\mathrm{P}(\mathrm{ClpP})$, which is located on the inner mitochondrial membrane, degrades mitochondrial proteins damaged by oxidative stress. The role of ClpP varies among tumor types. However, the expression pattern and biological functions of ClpP in breast cancer (BC) have not yet been investigated.

Methods. The Cancer Genome Atlas (TCGA) and Kaplan Meier-plotter database were used to analyze the expression level of ClpP in $\mathrm{BC}$ tissues, relationships with clinicopathological characteristics, and the influence on the prognosis of BC. Protein and mRNA expression levels of ClpP in BC cell lines and tissues were detected by quantitative real-time PCR, western blot and immunohistochemical (IHC) analyses. The colony formation assay, transwell assay and flow cytometric analysis were performed to assess various functions of ClpP. Western blot analysis was also conducted to determine the mechanism of ClpP. Results. ClpP expression was markedly increased in BC cells and tissues. High expression of ClpP was significantly correlated with the T stage, estrogen receptor (ER) expression, and poor recurrence-free survival (RFS) in TCGA and Kaplan Meier-plotter database. CIpP silencing significantly inhibited proliferation, migration, invasion, and promoted apoptosis of BC cells, which resulted in suppression of the Src/PI3K/Akt signaling pathway. The gainof-function assay confirmed partial these results. 
1 ClpP regulates breast cancer cell proliferation, invasion 2 and apoptosis by modulating the Src/PI3K/Akt signaling 3 pathway

Juan Luo ${ }^{1}$, Beilei Zeng ${ }^{1}$, Chunfang Tao ${ }^{1}$, Mengqi Lu${ }^{1}$, Guosheng Ren ${ }^{1,2, ~ *}$

${ }^{1}$ Chongqing Key Laboratory of Molecular Oncology and Epigenetics, The First Affiliated

8 Hospital of Chongqing Medical University, Chongqing 400016, P.R.China

$9 \quad{ }^{2}$ Department of Endocrine and Breast Surgery, The First Affiliated Hospital of Chongqing

Corresponding Author:

Guosheng Ren ${ }^{1,2}$

Chongqing Key Laboratory of Molecular Oncology and Epigenetics, The First Affiliated Hospital of Chongqing Medical University, No. 1 Youyi Road, Yuzhong District, Chongqing, 400016, China

Email address: rengs726@126.com

\section{Abstract}

Background. Caseinolytic protease $\mathrm{P}(\mathrm{ClpP})$, which is located on the inner mitochondrial membrane, degrades mitochondrial proteins damaged by oxidative stress. The role of ClpP varies among tumor types. However, the expression pattern and biological functions of $\mathrm{ClpP}$ in breast cancer (BC) have not yet been investigated.

Methods. The Cancer Genome Atlas (TCGA) and Kaplan Meier-plotter database were used to analyze the expression level of $\mathrm{ClpP}$ in $\mathrm{BC}$ tissues, relationships with clinicopathological characteristics, and the influence on the prognosis of BC. Protein and mRNA expression levels of $\mathrm{ClpP}$ in $\mathrm{BC}$ cell lines and tissues were detected by quantitative real-time PCR, western blot and immunohistochemical (IHC) analyses. The colony formation assay, transwell assay and flow cytometric analysis were performed to assess various functions of ClpP. Western blot analysis was also conducted to determine the mechanism of ClpP.

Results. ClpP expression was markedly increased in $\mathrm{BC}$ cells and tissues. High expression of ClpP was significantly correlated with the $\mathrm{T}$ stage, estrogen receptor (ER) expression, and poor recurrence-free survival (RFS) in TCGA and Kaplan Meier-plotter database. ClpP silencing significantly inhibited proliferation, migration, invasion, and promoted apoptosis of $\mathrm{BC}$ cells, which resulted in suppression of the Src/PI3K/Akt signaling pathway. The gain-of-function assay confirmed partial these results.

\section{Introduction}


39 Breast cancer $(\mathrm{BC})$ is the most common malignant tumor among women worldwide (Bray

40 et al. 2018). At present, the main treatment strategy for $\mathrm{BC}$ is surgical resection of the 41 breast and axillary lymph nodes, in combination with adjuvant therapies, which include

42 chemotherapy, radiotherapy, endocrine and targeted therapy. The rapid development of

43 deep sequencing and molecular biotechnologies have allowed for the identification of new

44 cancer targets and targeted therapeutic drugs.

45 The mitochondria have been a focus of cancer research since the 1950s, when it was

46 discovered that cancer cells produce adenosine triphosphate (ATP) and employ different

47 mechanisms to support cell growth than the normal surrounding tissues. Therefore, it was

48 suggested that a defect in the mitochondrial mechanism will not only lead to increased

49 glycolysis, but also to the transformation of normal cells into cancer cells (Warburg 1956).

50 The maintenance of mitochondrial function requires strict control of protein homeostasis

51 via independent mechanisms for protein synthesis and degradation. In addition to the

52 cytoplasmic ubiquitin/proteasome and protein quality control systems, the mitochondria of

53 mammalian cells have three ATP-dependent protease families: Lon (Wang et al. 1993),

54 FtsH (Banfi et al. 1999; Casari et al. 1998) and ClpXP (Corydon et al. 1998; Kang et al.

55 2002). These proteases regulate protein degradation and maintain protein quality control

56 (Goldberg 2003; Sauer et al. 2004). There is also evidence that an elevation to the proteostatic

57 threshold can lead to the onset of various diseases, especially cancer, and maintain the stability

58 of mitochondrial proteins in tumor cells (Seo et al. 2016).

59 The ClpXP protease complex is composed of two proteins: hexamers of a AAA+ ATPase

$60(\mathrm{ClpX})$ and the tetradecameric peptidase caseinolytic protease P (ClpP) (Bross et al. 1995;

61 Corydon et al. 1998; Kang et al. 2002), which contribute to the pathogenesis of human

62 disease (Gispert et al. 2013). A recent study reported that ClpXP is upregulated in primary

63 and metastatic human tumors, necessary to support tumor cell proliferation, motility and

64 heightened metastatic competence in vivo, and correlated with shortened survival. However,

65 the ClpP and ClpX subunits may not have completely overlapping function(s) in the tumor

66 mitochondria (Seo et al. 2016).

$67 \mathrm{ClpP}$ is encoded by nuclear genes in mammalian cells and plays a central role in the quality

68 control of mitochondrial proteins via the degradation of misfolded proteins. ClpP was first

69 identified in bacteria and has since aroused interest as a potential anti-microbial therapeutic

70 target (Zeiler et al. 2012). Studies have shown that bacterial ClpP inhibitors with a beta-

71 lactone structure have antibacterial activities (Bottcher \& Sieber 2008; Gersch et al. 2013;

72 Szyk \& Maurizi 2006). It has also been reported that mutations in human ClpP were

73 associated with Perrault syndrome (Jenkinson et al. 2013). However, few studies have

74 examined the role of ClpP in tumorigenesis.

75 The expression level of ClpP is greater in acute myeloid leukemia (AML) cells than in

76 normal hematopoietic cells (Cole et al. 2015). Further research found that ClpP

77 hyperactivation can lead to the death of leukemia and lymphoma cells due to selective

78 proteolysis of mitochondrial proteome subsets involved in mitochondrial respiration and 
79

80

81

82

83

84

85

86

87

88

89

90

91

92

93

94

95

96

97

98

99

100

101

102

103

104

105

106

107

108

109

110

111

112

113

114

115

116

117

118

oxidative phosphorylation (Ishizawa et al. 2019). Cancer stem cells and chemo-resistant cells are highly dependent on oxidative phosphorylation (Farge et al. 2017; Kuntz et al. 2017; Lagadinou et al. 2013; Marin-Valencia et al. 2012; Viale et al. 2014). Hence, ClpP could be exploited as a novel target in cancer treatment. Therefore, the aim of the present study was to explore the expression pattern, biological functions and underlying mechanisms of $\mathrm{ClpP}$ as a novel target for the treatment of $\mathrm{BC}$.

\section{Materials \& Methods}

\section{Tissue specimens}

Human BC tissues and corresponding adjacent normal tissues were collected from patients who underwent surgery at the First Affiliated Hospital of Chongqing Medical University from 2014 to 2018 , snap-frozen in liquid nitrogen, and then stored at $-80^{\circ} \mathrm{C}$. This study was approved by the Institutional Ethics Committees of the First Affiliated Hospital of Chongqing Medical University (approval no. 2019-208) and conducted in accordance with the tenets of the Declaration of Helsinki. Each participant signed an informed consent form prior to study inclusion.

\section{Cell culture}

Seven human BC cell lines (T47D, MCF-7, ZR-75-1, SK-BR-3, MDA-MB-231, MDA-MB468 and BT-549) and two normal mammary epithelial cell lines (MCF-10A and HBL-100) were obtained from the American Type Culture Collection (ATCC, Manassas, VA, USA). MCF-10A cells were cultured as described previously (Debnath et al. 2003) and all other cell lines were cultured in Roswell Park Memorial Institute 1640 medium (Gibco BRL, Karlsruhe, Germany) supplemented with 10\% fetal bovine serum (FBS) (Gibco BRL) at $37^{\circ} \mathrm{C}$ under a humidified atmosphere of $5 \% \mathrm{CO}_{2} / 95 \%$ air.

\section{Small interfering RNAs (siRNAs), plasmids, and transfection}

ClpP-specific and the negative control siRNAs were synthesized by OriGene (OriGene Technologies Inc., Rockville, MD, USA). The following siRNAs sequences were generated: SR305388A-rGrCrUrCrArArGrArArGrCrArGrCrUrCrUrArUrArArCrATC; SR305388B-rGrUrUrUrGrGrCrArUrCrUrUrArGrArCrArArGrGrUrUrCTG; and SR305388C-rGrGrCrCrArUrCrUrArCrGrArCrArCrGrArUrGrCrArGrUAC. The expression vector pCMV6-Myc-DDK-ClpP was produced by OriGene (OriGene Technologies Inc., Rockville, MD, USA); the empty pCMV6-Myc-DDK vector was used as a control. Lipofectamine 2000 (Invitrogen Corporation, Carlsbad, CA, USA) was used for siRNAs and plasmids transfection, in accordance with the manufacturer's protocols.

\section{RNA extraction and quantitative real-time PCR (RT-qPCR)}

Total RNA was extracted from cells and tissues with TRIzol reagent (Invitrogen) in accordance with the manufacturer's instructions. RT-qPCR was performed using an ABI 7500 Real-Time PCR System (Applied Biosystems, Foster City, CA, USA) with the SYBR Green kit (Invitrogen). $\beta$-actin was used as an internal control. Each sample was tested in triplicate. The followig primers were used for RT-qPCR analysis: ClpP, forward primer: 5'- 
119 GCC AAG CAC ACC AAA CAG A-3', reverse primer: 5'-GGA CCA GAA CCT TGT

120 CTA AG-3'; $\beta$-actin, forward primer: 5'-CCT GTG GCA TCC ACG AAA CT-3', reverse 121 primer: 5'-GAA GCA TTT GCG GTG GAC GAT-3'.

122 Western blot analysis

123 Total proteins were extracted with radioimmunoprecipitation assay lysis buffer (Thermo

124 Fisher Scientific, Waltham, MA, USA). Protein concentrations were determined using the

125 bicinchoninic acid protein assay kit (Pierce, Rockford, IL, USA). Western blot analysis was

126 conducted as previously described ( $\mathrm{Li}$ et al. 2018) with the following antibodies: anti-ClpP

127 (OriGene Technologies Inc., TA502075), anti-c-Src (Santa Cruz Biotechnology, sc-

128 130124), anti-p-Src (Santa Cruz Biotechnology, sc-166860), anti-PI3K (Santa Cruz

129 Biotechnology, sc-12930), anti-p-PI3K (Santa Cruz Biotechnology, sc-12929), anti-Akt

130 (Wanleibio, WL0003b), anti-p-Akt (Proteintech Group, 66444-1-ig), anti-caspase 3 (Santa

131 Cruz Biotechnology, sc-271759), anti-cleaved-caspase 9 (Wanleibio, WL01838), anti-

132 cleaved-caspase 8 (Wanleibio, WL0153), anti-cleaved PARP (Cell Signaling Technology,

133 \#9541), anti-MMP7 (Santa Cruz Biotechnology, sc-80205), anti-E-cadherin (Abcam,

134 ab40772), anti-vimentin (Santa Cruz Biotechnology, sc-965) and anti- $\beta$-actin (Santa Cruz

135 Biotechnology, sc-47778), anti-mouse IgG (Cell Signaling Technology, \#7076), anti-rabbit

136 IgG (Cell Signaling Technology, \#7074) and anti-goat IgG (Proteintech Group, SA00001-

137 4).

138 Immunohistochemical (IHC) analysis

139 All specimens were formalin-fixed, paraffin-embedded and cut into $4 \mu \mathrm{m}$-thick sections,

140 which were mounted onto glass slides. IHC analysis was conducted as described previously

141 (Li et al. 2018). Briefly, the slides were incubated with a primary antibody against ClpP

142 overnight at $4{ }^{\circ} \mathrm{C}$. Images were obtained using a Leica microscope equipped with a digital

143 camera (Leica Microsystems, Wetzlar, Germany) and the IHC results were analyzed using

144 Image-Pro Plus 6.0 software (Media Cybernetics, Bethesda, MA, USA). The grayscale

145 units were converted to optical density, units and the area and integrated optical density

146 (IOD) of the sections were then measured to calculate the mean optical density (MOD) for

147 semi-quantitative statistical analysis, where MOD $=$ total IOD/total area. The mean density

148 was calculated as IOD/area.

149 Cell apoptosis analysis

150 Cell apoptosis was detected with the Annexin V-FITC Apoptosis Detection Kit (BD

151 Biosciences, Franklin Lakes, NJ, USA) in accordance with the manufacturer's protocol and

152 a FACSCalibur flow cytometer (BD Biosciences).

153 Colony formation assay

154 MDA-MB-231 and ZR-75-1 cells were seeded into triplicate wells of 6-well plates at 1000 155 cells/well, and cultured for 7 days. The cells were then fixed with $4 \%$ paraformaldehyde 156 and stained with $0.1 \%$ crystal violet solution (C0121, Beyotime Institute of Biotechnology, 157 Haimen, China).

158 Cell migration and invasion assay 
159 Transwell chambers (8- $\mu$ m pore size; Corning, NY, USA) were used to detect the

160

161

162

163

164

165

166

167

168

169

170

171

172

173

174

175

176

177

178

179

180

181

182

183

184

185

186

187

188

189

190

191

192

193

194

195

196

197

198 migratory and invasive capabilities of BC cells. For the transwell migration assays, 200$\mu \mathrm{LL}$ aliquots of transfected MDA-MB-231, ZR-75-1, MCF-7 and T47D cells $\left(4 * 10^{4}\right.$ cells/well) were added into the upper transwell chamber, and $800 \mu \mathrm{L}$ of medium containing $10 \% \mathrm{FBS}$ were added to the lower chamber. After incubation at $37^{\circ} \mathrm{C}$ under an atmosphere of 5\% CO $2 / 95 \%$ air for $24 \mathrm{~h}$ (MDA-MB-231 and ZR-75-1 cells), or 72h (MCF-7 and T47D cells), cells that migrated through the membrane pores were fixed in $4 \%$ paraformaldehyde for 30 min and stained with $0.1 \%$ crystal violet (DC079; Genview, Beijing, China) for 15 min at room temperature. Matrigel ${ }^{\mathrm{TM}}$-coated transwell filters (Matrigel ${ }^{\mathrm{TM}}$ : serum-free medium $=1: 7,70 \mu \mathrm{l} /$ chamber) were used to evaluate the invasion capability of the cells. The subsequent procedures were the same as those for the cell migration assay. Cells from six random fields were counted under a microscope. All experiments were repeated three times.

\section{Database analysis}

TCGA dataset analyses

Gene expression data of BC tissues were downloaded from the TCGA database (https://tcga-data.nci.nih.gov/tcga/). The study cohort consisted of a total of $1010 \mathrm{BC}$ patients. ClpP expression data of 112 normal breast samples were included to compare differences in ClpP expression levels in BC tissues. Overall survival (OS) and complete clinicopathological data of 990 BC patients, and RFS data of 792 BC patients were screened. ClpP expression levels were ranked from low to high based on median values. The first $50 \%$ of patients were considered as the low-expression group and the second $50 \%$ as the high-expression group.

\section{Kaplan Meier-plotter dataset analyses}

Prognosis based on ClpP levels in BC patients was analyzed using the Kaplan Meier-plotter database (http://kmplot.com/analysis/).

\section{Statistical analysis}

Statistical analyses were performed using IBM SPSS Statistics for Windows, version 22.0 (Armonk, NY, USA) and GraphPad Prism 7.0 software (San Diego, CA, USA). The twotailed Student's $t$-test was used to compare two groups of independent samples. The chisquare test was used to assess the correlation between ClpP expression and the clinicopathological characteristics of BC patients. Kaplan-Meier analysis was performed to plot survival curves, which were compared with the log-rank test. A $p$-value $<0.05$ was regarded as statistically significant.

\section{Results}

ClpP is overexpressed in human BC tissues and associated with clinical outcomes ClpP expression levels in BC tissues were evaluated using the TCGA dataset. The results showed that ClpP expression was significantly up-regulated in BC tissues, as compared with normal tissues $(p<0.001)$ (Fig. 1A). Receiver operating characteristic (ROC) curve 
199

200

201

202

203

204

205

206

207

208

209

210

211

212

213

214

215

216

217

218

219

220

221

222

223

224

225

226

227

228

229

230

231

232

233

234

235

236

237

238

239

analysis was conducted to estimate the diagnostic value of ClpP. The area under the ROC curve (AUC) was 0.829 (95\% confidence interval $[\mathrm{CI}]=0.79-0.869, p<0.0001)$ (Fig. 1B). To verify the results, 18 pairs of $\mathrm{BC}$ and adjacent normal tissues were used for RT-qPCR analysis of ClpP expression levels. Consistently, ClpP expression was significantly increased in $\mathrm{BC}$ tissues, as compared with normal tissues $(p<0.01)$ (Fig. 1C). The AUC was $0.713(95 \% \mathrm{CI}=0.543-0.883, p=0.029)(\mathrm{Fig} .1 \mathrm{D})$. ClpP protein expression was also assessed by IHC analysis. As compared with normal tissues, cytoplasmic ClpP immunoreactivity was markedly higher in tumor tissues $(p<0.001)$ (Fig. 1E-G). These results showed that $\mathrm{ClpP}$ expression was significantly increased in $\mathrm{BC}$ tissues, suggesting high diagnostic potential. The clinical significance of $\mathrm{ClpP}$ in $\mathrm{BC}$ was assessed in tissues from 990 BC patients with complete clinicopathological characteristics (Table 1). High ClpP expression was found to be significantly associated with the T stage $(p=0.0154)$ and ER expression $(p=0.0164)$. Kaplan-Meier survival curves from TCGA indicated that ClpP was not associated with RFS ( $p=0.506)$ or OS $(p=0.619)$ (Fig. 2A and B). However, within the Kaplan Meier-plotter database, high ClpP expression was associated with poor RFS ( $p$ $=0.00071)$ (Fig. $2 \mathrm{C}$ and D). These results suggest that upregulation of ClpP was correlated with the T stage, ER expression, and poor RFS, suggesting a potential essential role in BC tumorigenesis.

Silencing of ClpP inhibits proliferation, migration, invasion and induces apoptosis of $\mathrm{BC}$ cells $\mathrm{ClpP}$ mRNA and protein expression levels in a panel of BC and normal breast epithelial cell lines were determined. The results showed that $\mathrm{ClpP}$ was increased in most malignant cell lines, as compared with normal cells (Fig. 3A and B). To further investigate the potential biological functions of $\mathrm{ClpP}$ in $\mathrm{BC}$, gain and loss-of-function studies were performed. The results showed that ClpP expression was significantly higher in MDA-MB231 and ZR-75-1 cells, but lower in MCF-7 and T47D cells. Thus, ClpP was knocked-down in MDA-MB-231 and ZR-75-1 cells, and overexpressed in MCF-7 and T47D cells. ClpP mRNA and protein expression was efficiently silenced by three different siRNAs in MDAMB-231 and ZR-75-1 cells (Fig. 3C-F), and overexpression efficiency in MCF-7 and T47D cells was confirmed by RT-qPCR (Supplementary Figure 1A).

The suppressive effect of ClpP silencing on cancer cell growth was confirmed by the colony formation assay. The colony formation capabilities of the BC cell lines MDA-MB231 and ZR-75-1 were markedly inhibited by si-ClpP-B $(p<0.01$ and $<0.001$, respectively) (Fig. 4A-E).

The transwell migration and invasion assay was performed to quantitatively assess cell metastasis and invasiveness. The results showed that cell migration and invasion were significantly reduced in cells transfected with si-ClpP-B, as compared with control cells, due to the down-regulation of MMP7 and vimentin, and the up-regulation of E-cadherin (Fig. 4F-Q and Fig. 5O-T). Conversely, the numbers of migratory and invasive MCF-7 and T47D cells were markedly increased by ClpP overexpression (Supplementary Figure 1B-E). Flow cytometry was carried out to detect cell apoptosis. The percentages of apoptotic MDA-MB-231 and ZR-75-1 cells were increased by si-ClpP-B $(p<0.01$ and $<0.001$, 
240 respectively), accompanied by increased levels of cleaved caspase-9, cleaved caspase-8 and 241 cleaved poly (ADP-ribose) polymerase (PARP) (Fig. 5A-N).

242 To confirm the specificity of ClpP siRNAs, the same functional experiments were performed

243 with a second siRNA (si-ClpP-A). The results of the loss-of-function studies were consistent

244 (Supplementary Figure 2).

245 These data revealed the anti-proliferative, anti-migration, anti-invasion and pro-apoptotic

246 roles of silencing ClpP in BC cells.

247 The tumor suppressive effect of silencing ClpP is mediated by the Src/PI3K/Akt signaling pathway

248 Previous studies have reported that the PI3K/Akt signaling pathway is involved in cellular

249 transformation, tumorigenesis, cancer progression, and proliferation of BC cells (Guerrero-

250 Zotano et al. 2016; Sharma et al. 2017). Further, ClpXP reported to mediate cell migration,

251 invasion, and metastasis in vivo by increasing phosphorylation of the key cellular kinases Akt

252 and Src (Seo et al. 2016). Here, western blot analysis was conducted to confirm whether the

$253 \mathrm{Src} / \mathrm{PI} \mathrm{K} / \mathrm{Akt}$ pathway is involved in ClpP-induced BC progression. As shown in Fig. 6,

254 silencing of ClpP inhibited the activation of Src, resulting in the inhibition of PI3K

255 phosphorylation and the downstream signaling molecule Akt, which led to a series of

256 changes in the activities of related molecules associated with cell proliferation, apoptosis,

257 migration and invasion. These data confirmed the effect of ClpP on the proliferation and

258 invasion capabilities of MDA-MB-231 and ZR-75-1 BC cells, as well as the induction of

259 apoptosis.

260

261

\section{Discussion}

262

263

A 2016 study conducted by Seo et al. found that ClpP was overexpressed in almost all

264 human malignancies, as determined by immunohistochemical staining of a universal cancer

265 tissue microarray (Seo et al. 2016). In the study, ClpP expression was significantly upregulated in both $\mathrm{BC}$ cell lines and tissues, which was consistent with previous findings.

266 More, Jo Ishizawa et al. reported that hyperactivation of $\mathrm{ClpP}$ could be a therapeutic

267 strategy for patients with high $\mathrm{ClpP}$ expression, and that lower expression of $\mathrm{ClpP}$ was

268 associated with reduced sensitivity to ClpP hyperactivation in ALM (Ishizawa et al. 2019). Therefore, we can infer that high expression of ClpP presents not only a new therapeutic target

270 for $\mathrm{BC}$, but is also predictive of sensitivity to treatment. Seo et al. reported that $\mathrm{ClpP}$ expression

271 is related to the histotype of breast adenocarcinoma (Seo et al. 2016). Likewise, the results of the

272 present study showed that $\mathrm{ClpP}$ expression was closely correlated with the T stage and ER

273 expression in $\mathrm{BC}$, thereby demonstrating a link between $\mathrm{ClpP}$ expression and the clinical

274 characteristics of $\mathrm{BC}$ patients.

275 The results of bioinformatics and a meta-analysis revealed that $\mathrm{ClpP}$ expression was

276 associated with a poorer outcome in 9 (64.3\%) of 14 analyzed datasets. Importantly, high

277 ClpP expression was correlated with shorter metastasis-free survival in BC patients and

278 reduced RFS in those with lung adenocarcinoma (Seo et al. 2016). Consistent with previous

279 studies, the results of the present study showed that ClpP was not significantly correlated 
280

281

282

283

284

285

286

287

288

289

290

291

292

293

294

295

296

297

298

299

300

301

302

303

304

305

306

307

308

309

310

311

312

313

314

315

316

317

318

319

with OS and RFS using the TCGA dataset. However, in the Kaplan Meier-plotter database, which contains a larger sample size, high ClpP expression was associated with poor RFS in $\mathrm{BC}$ patients. To the best of our knowledge, the number of clinical samples determines the possible relationship between ClpP expression and survival of BC patients. The Kaplan Meier-plotter database includes data from TCGA and GEO chips, which overlap with but greatly exceed the TCGA database. Further, survival analysis of 537 French BC patients from the EMTAB-365 database with the Kaplan Meier-plotter showed that differences in diagnostic criteria, treatment regimens, and regions will result in differences in survival benefits of the same disease, suggesting that more comprehensive information must be obtained from diverse databases in order to address these issues in future studies.

ClpP is a subunit of the ClpXP complex. Seo et al. found that ClpXP was associated with tumor cell migration, invasion and metastasis (Seo et al. 2016). Consistent with these findings, the results of the present study suggest that silencing of $\mathrm{ClpP}$ inhibited $\mathrm{BC}$ cell proliferation, migration and invasion, and induced apoptosis.

The Akt signaling pathway is important in the regulation of various cellular functions, including metabolism, growth, proliferation, survival, transcription, protein synthesis and tumorigenesis (Aoki \& Fujishita 2017). Mutations in the PI3K/Akt pathway can reportedly mediate development, progression and drug resistance of BC (Guerrero-Zotano et al. 2016; Sharma et al. 2017). Src can bind to different subtypes of the integrin family, which affects the motility and metastasis of tumor cells. Picon-Ruiz et al. found that the invasion of localized fat by cancer cells will activate Src, maintain the production of pro-inflammatory cytokines, and promote metastasis of BC cells (Picon-Ruiz et al. 2016). The results of the present study demonstrated that phosphorylation of Src, PI3K and Akt was markedly downregulated by silencing ClpP. These findings provide powerful evidence that silencing ClpP contributes to inactivation of the Src/PI3K/Akt pathway in BC.

In summary, the present study provides the first evidence that $\mathrm{ClpP}$ is frequently upregulated in $\mathrm{BC}$ and that $\mathrm{ClpP}$ has high diagnostic value.

\section{Conclusions}

ClpP expression is markedly increased in BC and significantly correlated with the $\mathrm{T}$ stage, ER expression, and poor RFS. Silencing of ClpP significantly inhibited proliferation, migration and invasion, and promoted apoptosis of BC cells, resulting in suppression of the $\mathrm{Src} / \mathrm{PI}$ K/Akt signaling pathway. These data indicate that ClpP is an oncogene, and may be a promising diagnostic biomarker and therapeutic target in $\mathrm{BC}$.

\section{Acknowledgements}

We thank Professor Guosheng Ren for his support in writing this article and our tutors and friends for their help and encouragement.

\section{References}


320

321

322

323

324

325

326

327

328

329

330

331

332

333

334

335

336

337

338

339

340

341

342

343

344

345

346

347

348

349

350

351

352

353

354

355

356

357

358

359

360

361

362

363

364

365

366

367

368

369

370

NCCN Clinical Practice Guidelines in Oncology: Breast Cancer (Version 2.2019). 02 Jul 2019 ed: National Comprehensive Cancer Network.

Aoki M, and Fujishita T. 2017. Oncogenic Roles of the PI3K/AKT/mTOR Axis. Curr Top Microbiol Immunol 407:153-189. 10.1007/82_2017_6

Banfi S, Bassi MT, Andolfi G, Marchitiello A, Zanotta S, Ballabio A, Casari G, and Franco B. 1999. Identification and characterization of AFG3L2, a novel paraplegin-related gene. Genomics 59:51-58. 10.1006/geno.1999.5818

Bottcher T, and Sieber SA. 2008. Beta-lactones as specific inhibitors of ClpP attenuate the production of extracellular virulence factors of Staphylococcus aureus. J Am Chem Soc 130:14400-14401. 10.1021/ja8051365

Bray F, Ferlay J, Soerjomataram I, Siegel RL, Torre LA, and Jemal A. 2018. Global cancer statistics 2018: GLOBOCAN estimates of incidence and mortality worldwide for 36 cancers in 185 countries. CA Cancer J Clin 68:394-424. 10.3322/caac.21492

Bross P, Andresen BS, Knudsen I, Kruse TA, and Gregersen N. 1995. Human ClpP protease: cDNA sequence, tissue-specific expression and chromosomal assignment of the gene. FEBS Lett 377:249-252. 10.1016/0014-5793(95)01353-9

Casari G, De Fusco M, Ciarmatori S, Zeviani M, Mora M, Fernandez P, De Michele G, Filla A, Cocozza S, Marconi R, Durr A, Fontaine B, and Ballabio A. 1998. Spastic paraplegia and OXPHOS impairment caused by mutations in paraplegin, a nuclear-encoded mitochondrial metalloprotease. Cell 93:973-983. 10.1016/s0092-8674(00)81203-9

Cole A, Wang Z, Coyaud E, Voisin V, Gronda M, Jitkova Y, Mattson R, Hurren R, Babovic S, Maclean N, Restall I, Wang X, Jeyaraju DV, Sukhai MA, Prabha S, Bashir S, Ramakrishnan A, Leung E, Qia YH, Zhang N, Combes KR, Ketela T, Lin F, Houry WA, Aman A, Al-Awar R, Zheng W, Wienholds E, Xu CJ, Dick J, Wang JC, Moffat J, Minden MD, Eaves CJ, Bader GD, Hao Z, Kornblau SM, Raught B, and Schimmer AD. 2015. Inhibition of the Mitochondrial Protease ClpP as a Therapeutic Strategy for Human Acute Myeloid Leukemia. Cancer Cell 27:864-876. 10.1016/j.ccell.2015.05.004

Corydon TJ, Bross P, Holst HU, Neve S, Kristiansen K, Gregersen N, and Bolund L. 1998. A human homologue of Escherichia coli ClpP caseinolytic protease: recombinant expression, intracellular processing and subcellular localization. Biochem $J 331(\mathrm{Pt}$ 1):309-316. 10.1042/bj3310309

Debnath J, Muthuswamy SK, and Brugge JS. 2003. Morphogenesis and oncogenesis of MCF$10 \mathrm{~A}$ mammary epithelial acini grown in three-dimensional basement membrane cultures. Methods 30:256-268. 10.1016/s1046-2023(03)00032-x

Farge T, Saland E, de Toni F, Aroua N, Hosseini M, Perry R, Bosc C, Sugita M, Stuani L, Fraisse M, Scotland S, Larrue C, Boutzen H, Feliu V, Nicolau-Travers ML, CassantSourdy S, Broin N, David M, Serhan N, Sarry A, Tavitian S, Kaoma T, Vallar L, lacovoni J, Linares LK, Montersino C, Castellano R, Griessinger E, Collette Y, Duchamp O, Barreira Y, Hirsch P, Palama T, Gales L, Delhommeau F, Garmy-Susini BH, Portais JC, Vergez F, Selak M, Danet-Desnoyers G, Carroll M, Recher C, and Sarry JE. 2017. Chemotherapy-Resistant Human Acute Myeloid Leukemia Cells Are Not Enriched for Leukemic Stem Cells but Require Oxidative Metabolism. Cancer Discov 7:716-735. 10.1158/2159-8290.cd-16-0441

Gersch M, Gut F, Korotkov VS, Lehmann J, Bottcher T, Rusch M, Hedberg C, Waldmann H, Klebe G, and Sieber SA. 2013. The mechanism of caseinolytic protease (ClpP) inhibition. Angew Chem Int Ed Engl 52:3009-3014. 10.1002/anie.201204690

Gispert S, Parganlija D, Klinkenberg M, Drose S, Wittig I, Mittelbronn M, Grzmil P, Koob S, Hamann A, Walter M, Buchel F, Adler T, Hrabe de Angelis M, Busch DH, Zell A, Reichert AS, Brandt U, Osiewacz HD, Jendrach M, and Auburger G. 2013. Loss of mitochondrial peptidase Clpp leads to infertility, hearing loss plus growth retardation via accumulation of CLPX, mtDNA and inflammatory factors. Hum Mol Genet 22:4871-4887.

Peer) reviewing PDF | (2019:10:42537:1:2:NEW 22 Jan 2020) 
371

372

373

374

375

376

377

378

379

380

381

382

383

384

385

386

387

388

389

390

391

392

393

394

395

396

397

398

399

400

401

402

403

404

405

406

407

408

409

410

411

412

413

414

415

416

417

418

419

420

421

10.1093/hmg/ddt338

Goldberg AL. 2003. Protein degradation and protection against misfolded or damaged proteins. Nature 426:895-899. 10.1038/nature02263

Guerrero-Zotano A, Mayer IA, and Arteaga CL. 2016. PI3K/AKT/mTOR: role in breast cancer progression, drug resistance, and treatment. Cancer Metastasis Rev 35:515-524. 10.1007/s10555-016-9637-x

Ishizawa J, Zarabi SF, Davis RE, Halgas O, Nii T, Jitkova Y, Zhao R, St-Germain J, Heese LE, Egan G, Ruvolo VR, Barghout SH, Nishida Y, Hurren R, Ma W, Gronda M, Link T, Wong K, Mabanglo M, Kojima K, Borthakur G, MacLean N, Ma MCJ, Leber AB, Minden MD, Houry W, Kantarjian H, Stogniew M, Raught B, Pai EF, Schimmer AD, and Andreeff M. 2019. Mitochondrial CIpP-Mediated Proteolysis Induces Selective Cancer Cell Lethality. Cancer Cell 35:721-737.e729. 10.1016/j.ccell.2019.03.014

Jenkinson EM, Rehman AU, Walsh T, Clayton-Smith J, Lee K, Morell RJ, Drummond MC, Khan SN, Naeem MA, Rauf B, Billington N, Schultz JM, Urquhart JE, Lee MK, Berry A, Hanley NA, Mehta S, Cilliers D, Clayton PE, Kingston H, Smith MJ, Warner TT, Black GC, Trump D, Davis JR, Ahmad W, Leal SM, Riazuddin S, King MC, Friedman TB, and Newman WG. 2013. Perrault syndrome is caused by recessive mutations in CLPP, encoding a mitochondrial ATP-dependent chambered protease. Am J Hum Genet 92:605-613. 10.1016/j.ajhg.2013.02.013

Kang SG, Ortega J, Singh SK, Wang N, Huang NN, Steven AC, and Maurizi MR. 2002. Functional proteolytic complexes of the human mitochondrial ATP-dependent protease, hCIpXP. J Biol Chem 277:21095-21102. 10.1074/jbc.M201642200

Kuntz EM, Baquero P, Michie AM, Dunn K, Tardito S, Holyoake TL, Helgason GV, and Gottlieb E. 2017. Targeting mitochondrial oxidative phosphorylation eradicates therapy-resistant chronic myeloid leukemia stem cells. Nat Med 23:1234-1240. 10.1038/nm.4399

Lagadinou ED, Sach A, Callahan K, Rossi RM, Neering SJ, Minhajuddin M, Ashton JM, Pei S, Grose V, O'Dwyer KM, Liesveld JL, Brookes PS, Becker MW, and Jordan CT. 2013. BCL-2 inhibition targets oxidative phosphorylation and selectively eradicates quiescent human leukemia stem cells. Cell Stem Cell 12:329-341. 10.1016/j.stem.2012.12.013

Li Y, Huang J, Zeng B, Yang D, Sun J, Yin X, Lu M, Qiu Z, Peng W, Xiang T, Li H, and Ren G. 2018. PSMD2 regulates breast cancer cell proliferation and cell cycle progression by modulating p21 and p27 proteasomal degradation. Cancer Lett 430:109-122. 10.1016/j.canlet.2018.05.018

Marin-Valencia I, Yang C, Mashimo T, Cho S, Baek H, Yang XL, Rajagopalan KN, Maddie M, Vemireddy V, Zhao Z, Cai L, Good L, Tu BP, Hatanpaa KJ, Mickey BE, Mates JM, Pascual JM, Maher EA, Malloy CR, Deberardinis RJ, and Bachoo RM. 2012. Analysis of tumor metabolism reveals mitochondrial glucose oxidation in genetically diverse human glioblastomas in the mouse brain in vivo. Cell Metab 15:827-837. 10.1016/j.cmet.2012.05.001

Picon-Ruiz M, Pan C, Drews-Elger K, Jang K, Besser AH, Zhao D, Morata-Tarifa C, Kim M, Ince TA, Azzam DJ, Wander SA, Wang B, Ergonul B, Datar RH, Cote RJ, Howard GA, ElAshry D, Torne-Poyatos P, Marchal JA, and Slingerland JM. 2016. Interactions between Adipocytes and Breast Cancer Cells Stimulate Cytokine Production and Drive Src/Sox2/miR-302b-Mediated Malignant Progression. Cancer Res 76:491-504. 10.1158/0008-5472.can-15-0927

Sauer RT, Bolon DN, Burton BM, Burton RE, Flynn JM, Grant RA, Hersch GL, Joshi SA, Kenniston JA, Levchenko I, Neher SB, Oakes ES, Siddiqui SM, Wah DA, and Baker TA. 2004. Sculpting the proteome with $\mathrm{AAA}(+)$ proteases and disassembly machines. Cell 119:9-18. 10.1016/j.cell.2004.09.020

Seo JH, Rivadeneira DB, Caino MC, Chae YC, Speicher DW, Tang HY, Vaira V, Bosari S, Palleschi A, Rampini P, Kossenkov AV, Languino LR, and Altieri DC. 2016. The

Peer) reviewing PDF | (2019:10:42537:1:2:NEW 22 Jan 2020) 
422

423

424

425

426

427

428

429

430

431

432

433

434

435

436

437

438

439

440

441

442

443
Mitochondrial Unfoldase-Peptidase Complex CIpXP Controls Bioenergetics Stress and Metastasis. PLoS Biol 14:e1002507. 10.1371/journal.pbio.1002507

Sharma VR, Gupta GK, Sharma AK, Batra N, Sharma DK, Joshi A, and Sharma AK. 2017. PI3K/Akt/mTOR Intracellular Pathway and Breast Cancer: Factors, Mechanism and Regulation. Curr Pharm Des 23:1633-1638. 10.2174/1381612823666161116125218

Szyk A, and Maurizi MR. 2006. Crystal structure at 1.9A of E. coli ClpP with a peptide covalently bound at the active site. J Struct Biol 156:165-174. 10.1016/j.jsb.2006.03.013

Viale A, Pettazzoni P, Lyssiotis CA, Ying H, Sanchez N, Marchesini M, Carugo A, Green T, Seth S, Giuliani V, Kost-Alimova M, Muller F, Colla S, Nezi L, Genovese G, Deem AK, Kapoor A, Yao W, Brunetto E, Kang Y, Yuan M, Asara JM, Wang YA, Heffernan TP, Kimmelman AC, Wang H, Fleming JB, Cantley LC, DePinho RA, and Draetta GF. 2014. Oncogene ablation-resistant pancreatic cancer cells depend on mitochondrial function. Nature 514:628-632. 10.1038/nature13611

Wang N, Gottesman S, Willingham MC, Gottesman MM, and Maurizi MR. 1993. A human mitochondrial ATP-dependent protease that is highly homologous to bacterial Lon protease. Proc Natl Acad Sci U S A 90:11247-11251. 10.1073/pnas.90.23.11247

Warburg O. 1956. On the origin of cancer cells. Science 123:309-314. 10.1126/science.123.3191.309

Zeiler E, Korotkov VS, Lorenz-Baath K, Bottcher T, and Sieber SA. 2012. Development and characterization of improved beta-lactone-based anti-virulence drugs targeting ClpP. Bioorg Med Chem 20:583-591. 10.1016/j.bmc.2011.07.047 


\section{Figure 1}

ClpP is overexpressed in BC

(A) The expression levels of ClpP were analyzed in 1010 BC tissues and 112 normal tissues in TCGA cohort. Values are presented as the mean \pm SD (unpaired $t$-test). (B) ROC curve analysis of ClpP expression in TCGA cohort. (C) Comparison of ClpP expression in 18 paired $\mathrm{BC}$ and adjacent normal tissues by RT-qPCR. Values are presented as the mean \pm SD (paired $t$-test). (D) ROC curve analysis of ClpP expression in the 18 paired tissues. $(E, F)$

Representative IHC images of ClpP protein expression in BC and adjacent normal tissues. (G) Histogram of IHC scores of ClpP in 29 BC cases and 24 normal samples. Data are presented as the mean \pm SD (unpaired $t$-test). ${ }^{* *} p<0.01,{ }^{* * *} p<0.001$. 
A

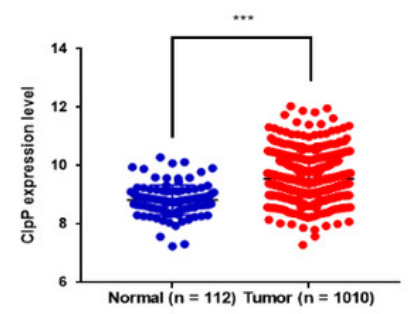

C

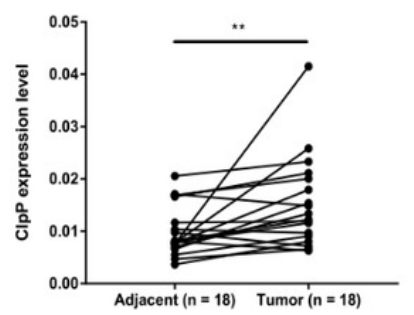

B

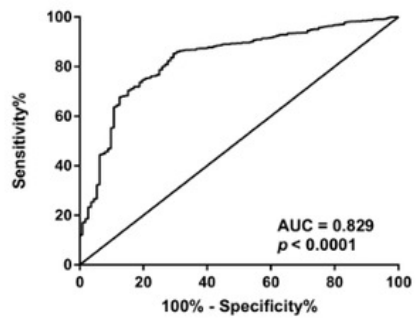

D

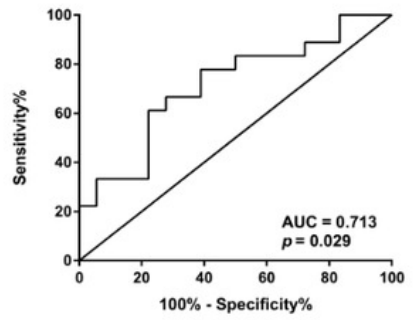

E

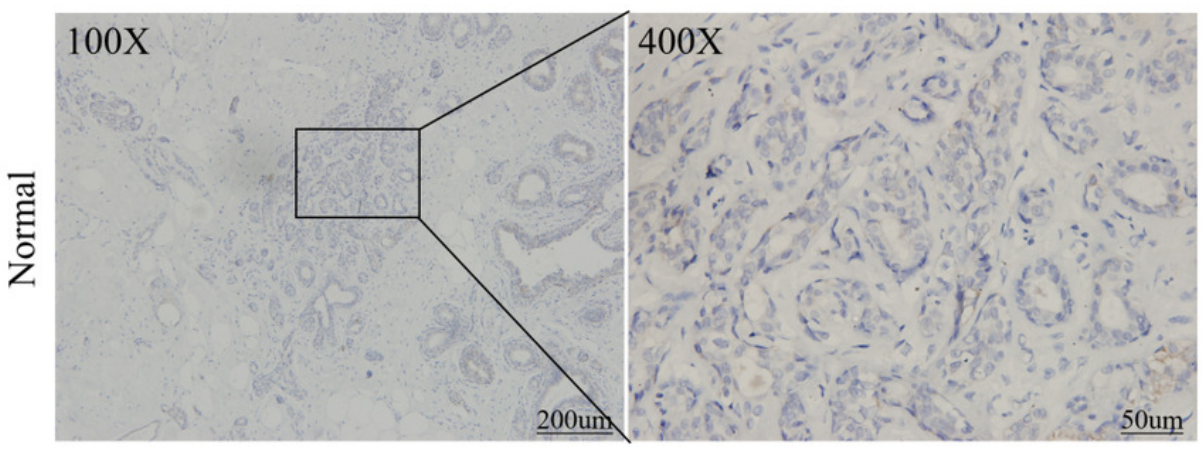

F

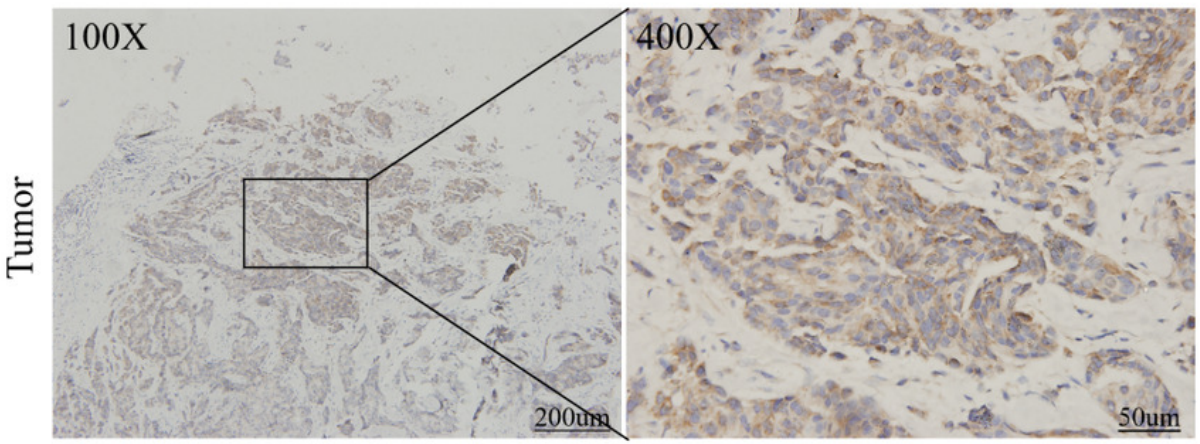

G

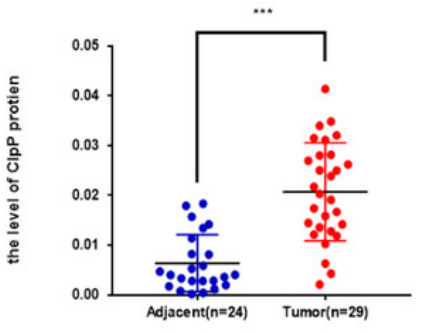

Peer] reviewing PDF | (2019:10:42537:1:2:NEW 22 Jan 2020) 


\section{Figure 2}

Overexpressed CIpP is associated with poor RFS

(A, B) Kaplan-Meier analysis of RFS (A) and OS (B) in patients with BC in TCGA database. For RFS analysis, the patients were assigned to the ClpP high $(n=396)$ or ClpP low $(n=396)$ group. For OS analysis, the patients were assigned to the ClpP high $(n=495)$ or ClpP low ( = 495) group based on the median value of ClpP expression. (C, D) Kaplan Meier-plotter database analysis of the relationships between CIpP expression and clinical outcomes (RFS and OS). For RFS analysis, the patients were assigned to the ClpP high ( $n=1972$ ) or ClpP low $(n=1979)$ group. For OS analysis, the patients were assigned to the ClpP high $(n=697)$ or ClpP low $(n=705)$ group. 
A

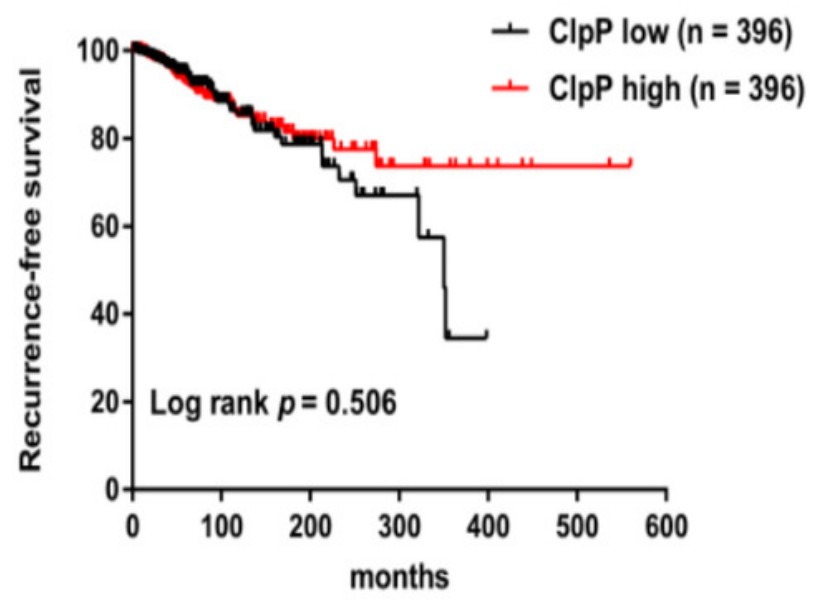

C

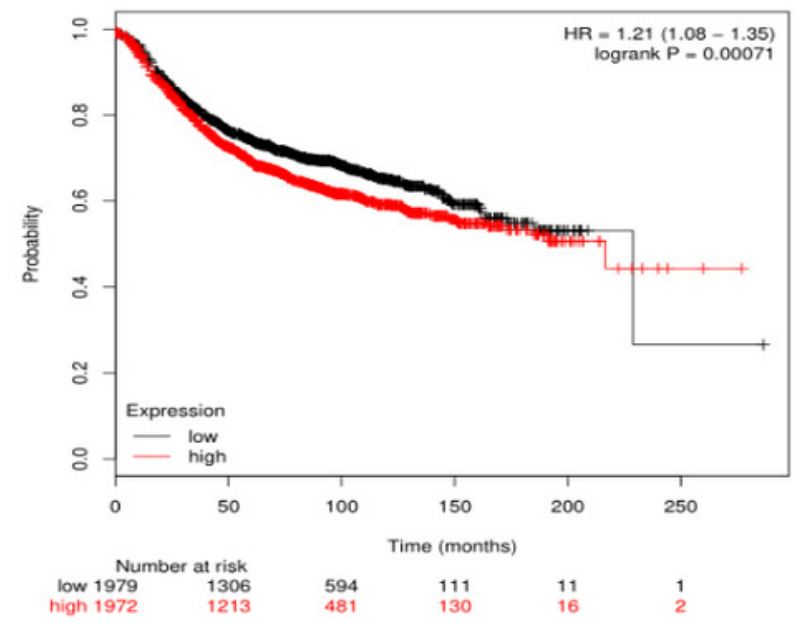

B

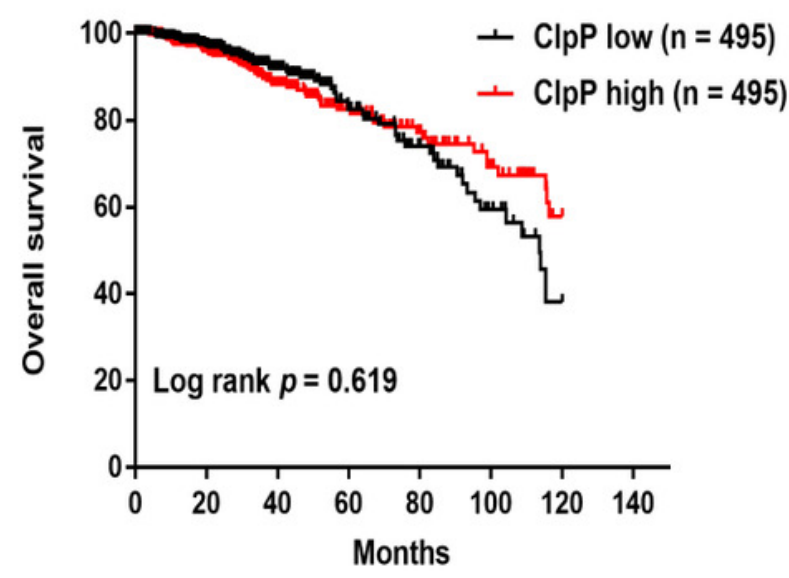

D

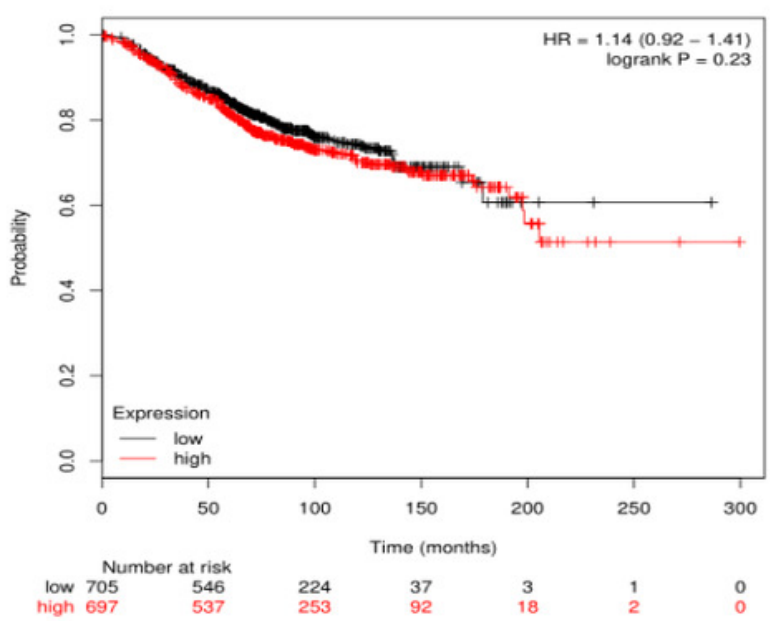




\section{Figure 3}

ClpP mRNA and protein expression in a panel of BC and normal breast epithelial cell lines

(A) RT-qPCR analysis of ClpP mRNA expression levels in BC cells, as compared to MCF-10A cells. (B) ClpP protein expression levels in BC cells by western blot analysis, as compared to MCF-10A cells. (C, D) ClpP expression levels were measured after transfection with three different siRNAs or negative controls (NC) in MDA-MB-231 and ZR-75-1 cells using RT-qPCR. $(\mathrm{E}, \mathrm{F}) \mathrm{ClpP}$ expression levels were measured after transfection with three different siRNAs or negative controls (NC) in MDA-MB-231 and ZR-75-1 cells using western blot analyses. The data are presented as the mean $\pm \mathrm{SD},{ }^{*} p<0.05,{ }^{* *} p<0.01,{ }^{* *} p<0.001$. 
A

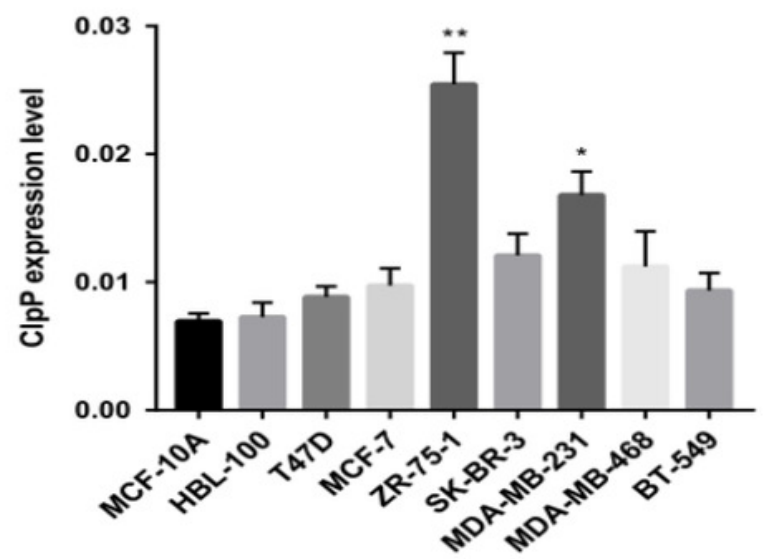

C

MDA-MB-231

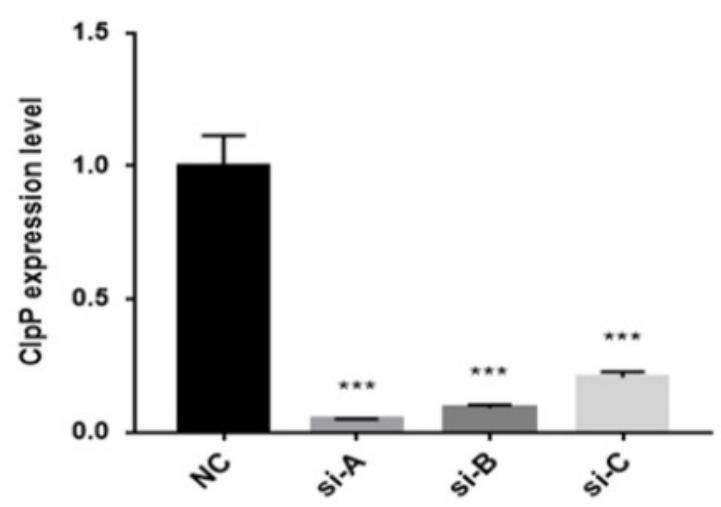

E

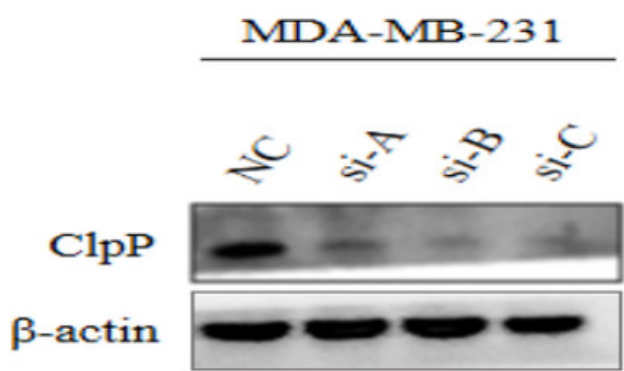

B

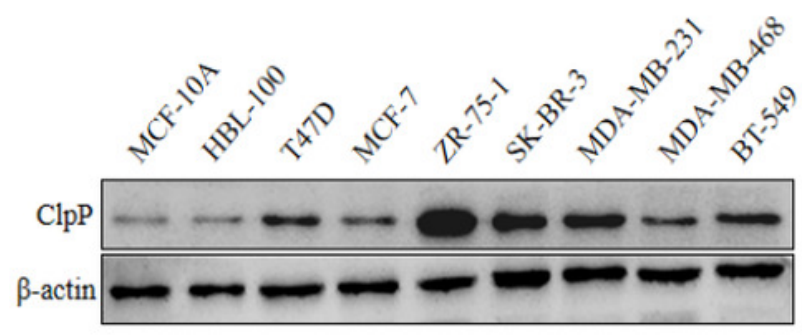

D

ZR-75-1

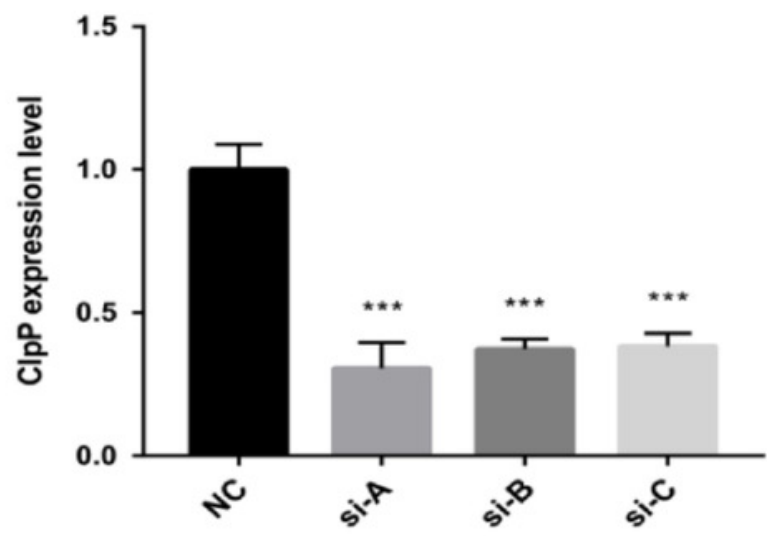

F

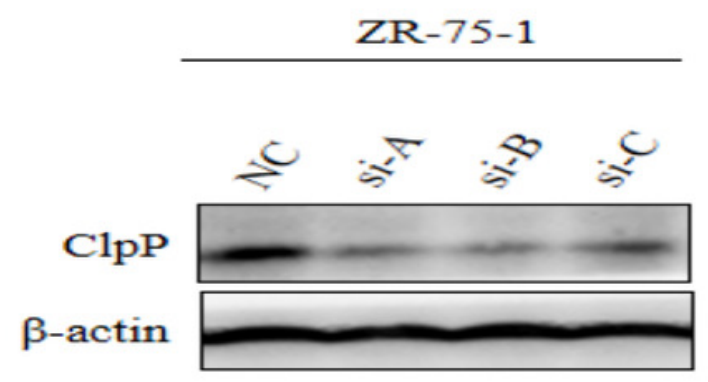


Figure 4

Silencing of ClpP-B inhibits proliferation, migration and invasion of BC cells

(A-E)The effects of si-ClpP-B on BC cell proliferation were analyzed using the colony formation assay. (F-K) The effects of si-ClpP-B on BC cell migration were evaluated using the transwell assay. (L-Q) The effects of si-ClpP-B on BC cell invasion were evaluated using the transwell assay. The data are presented as the mean $\pm \mathrm{SD},{ }^{* *} p<0.01,{ }^{* * *} p<0.001$. 

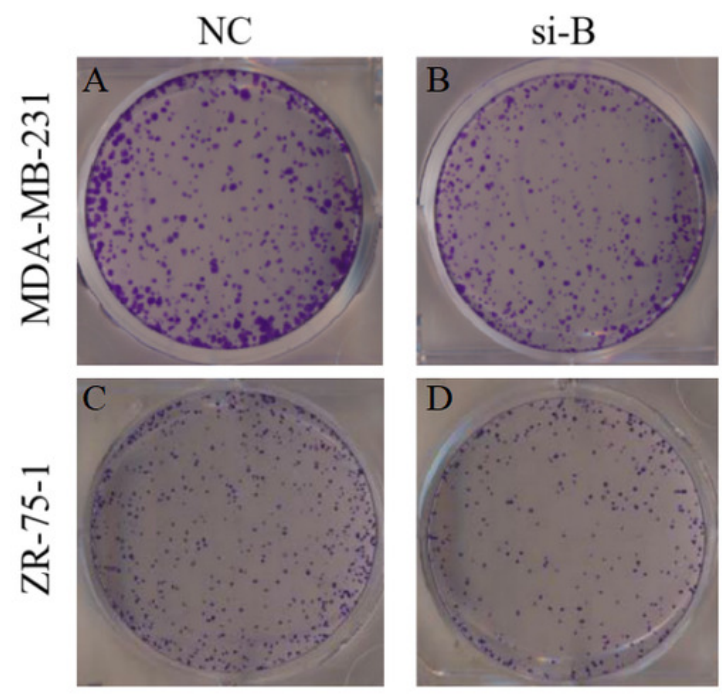

\section{$\mathrm{NC}$}
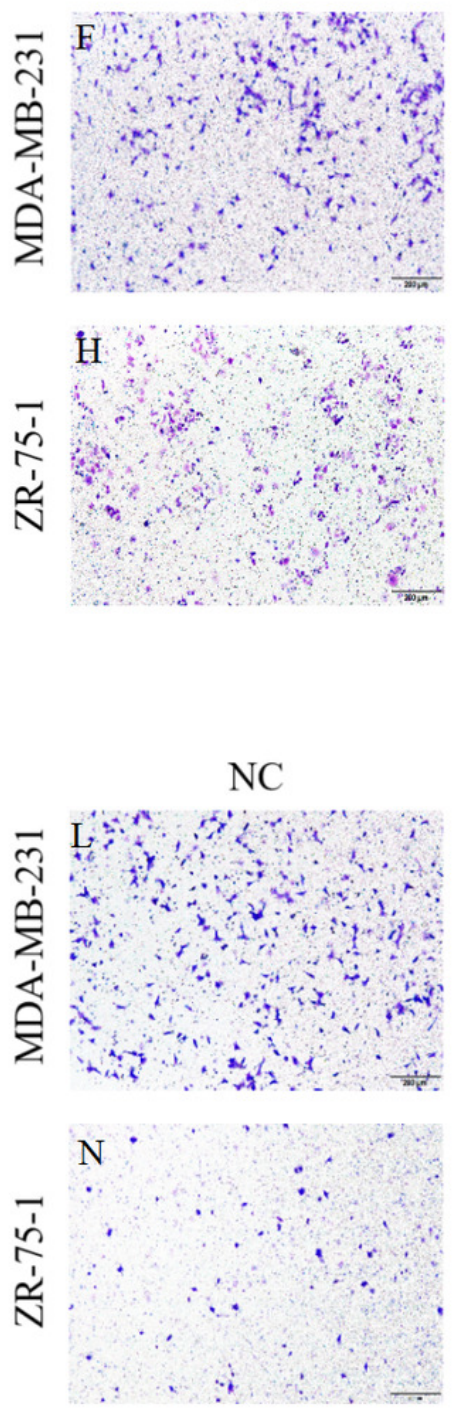

E

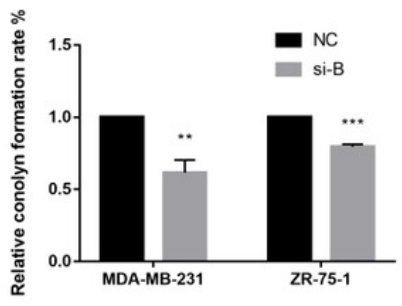

K
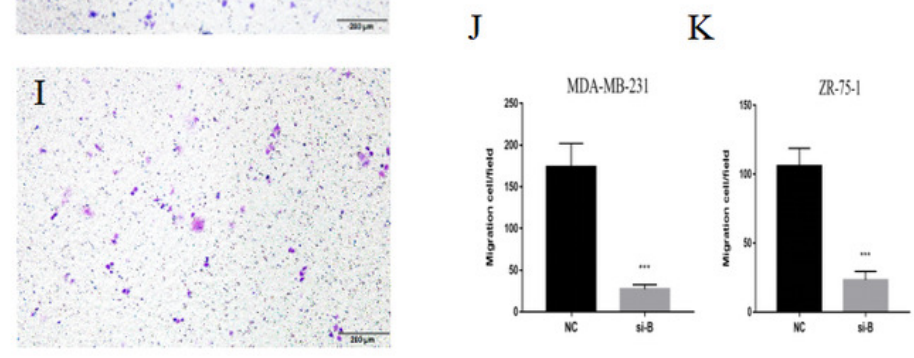


\section{Figure 5}

Silencing of ClpP-B induces apoptosis of BC cells

(A-C) The effect of si-ClpP-B in MDA-MB-231 apoptosis was analyzed using flow cytometry. (D-

F) The effect of si-ClpP-B in ZR-75-1 apoptosis was analyzed using flow cytometry.(G-V)

Western blots showing upregulation of the apoptotic markers (cleaved caspase-9, cleaved caspase-8 and cleaved PARP), the upregulated metastasis and invasiveness marker Ecadherin and down-regulated markers MMP7 and vimentin of the si-ClpP-B in MDA-MB-231 and ZR-75-1 cells. The data are presented as the mean \pm SD, ${ }^{* *} p<0.01,{ }^{* * *} p<0.001$. 
A

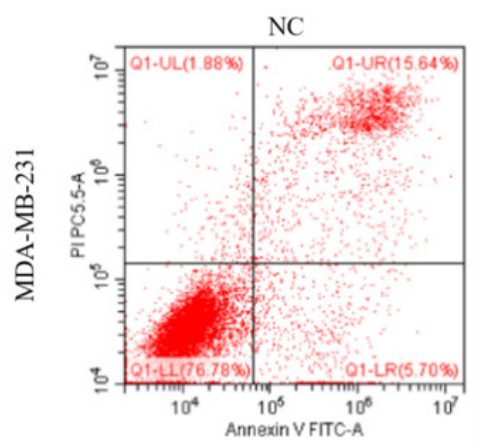

D

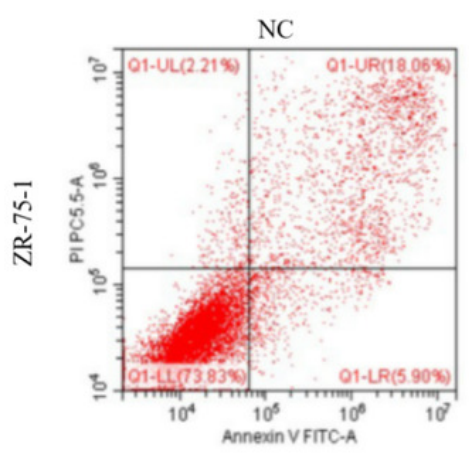

B

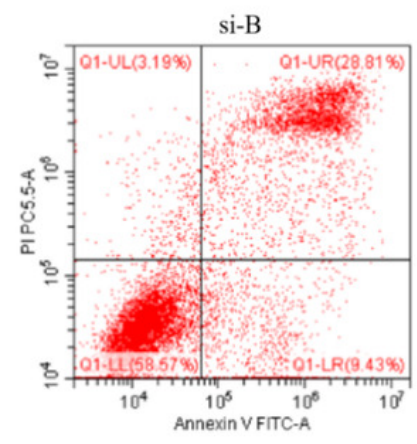

E

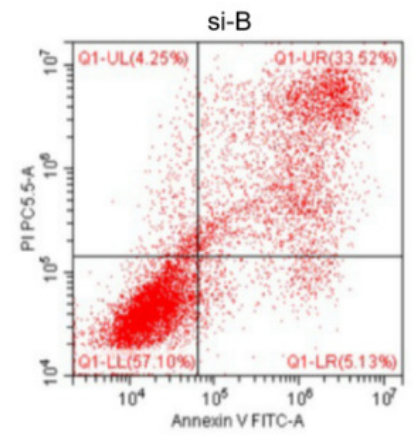

C

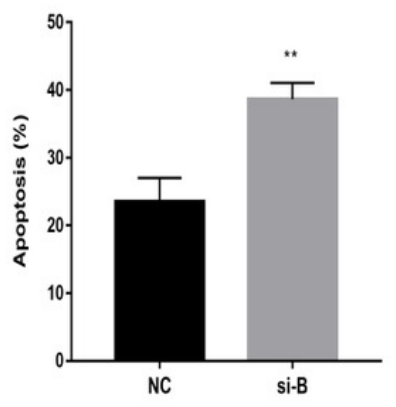

F

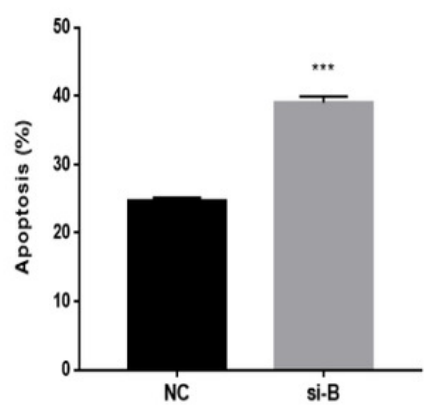

\section{MDA-MB-231 ZR-75-1}

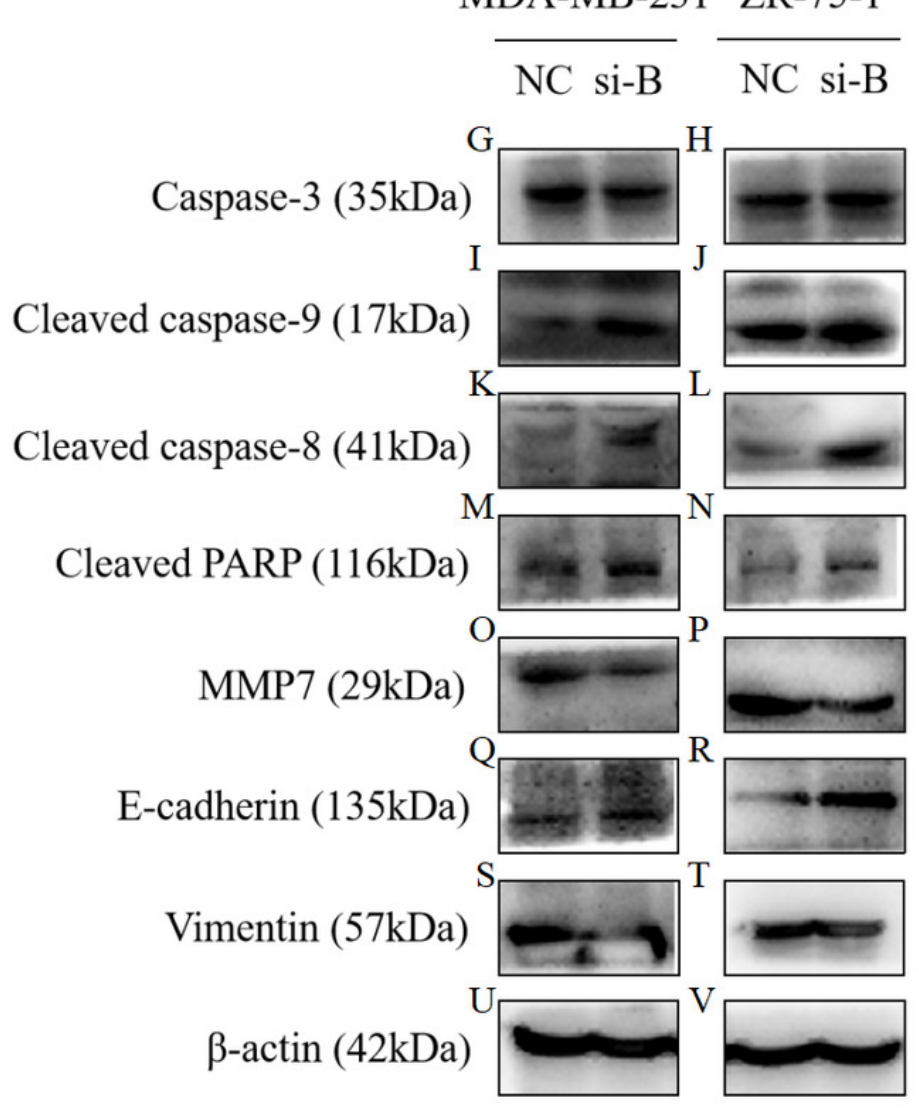




\section{Figure 6}

Silencing ClpP inhibits Src/PI3K/Akt signaling in MDA-MB-231 and ZR-75-1 cells

(A, B) Western blot of Src in MDA-MB-231 and ZR-75-1. (C, D) Western blot of p-Src in MDAMB-231 and ZR-75-1. (E, F)Western blot of Akt in MDA-MB-231 and ZR-75-1. (G, H) Western blot of p-Akt in MDA-MB-231 and ZR-75-1. (I, J) Western blot of PI3K in MDA-MB-231 and ZR-75-1. (K, L) Western blot of p-PI3K in MDA-MB-231 and ZR-75-1. (M, N) Western blot of $\beta$ actin as a control. 


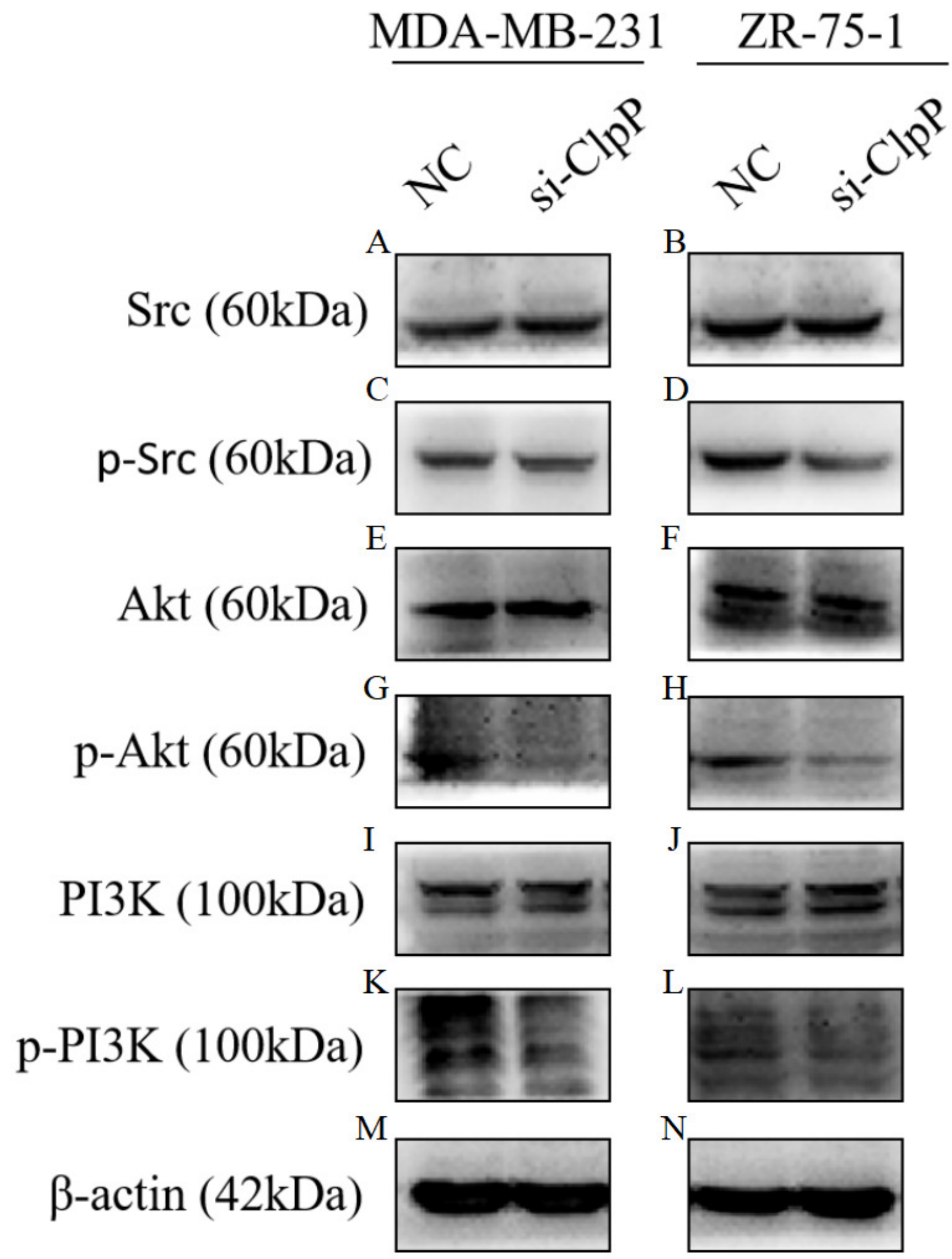




\section{Table $\mathbf{1}$ (on next page)}

Correlation analysis between ClpP expression levels and clinicopathological characteristics of $990 \mathrm{BC}$ patients in TCGA 
1 Table 1:

2 Correlation analysis between CIpP expression levels and clinicopathological

3 characteristics of 990 BC patients in TCGA.

\begin{tabular}{|c|c|c|c|c|c|}
\hline \multirow[b]{2}{*}{ Characteristic } & \multirow[b]{2}{*}{ Number } & \multicolumn{2}{|c|}{ ClpP expression } & \multirow[b]{2}{*}{$x^{2}$} & \multirow[b]{2}{*}{$p$-value } \\
\hline & & $\begin{array}{l}\text { Low } \\
(\mathrm{n}=495)\end{array}$ & $\begin{array}{l}\text { High } \\
(\mathrm{n}=495)\end{array}$ & & \\
\hline Age (years) & & & & 2.405 & 0.1209 \\
\hline$<55$ & 406 & 215 & 191 & & \\
\hline$\geq 55$ & 584 & 280 & 304 & & \\
\hline T Stage & & & & 10.4 & $0.0154^{*}$ \\
\hline Tx-1 & 261 & 145 & 116 & & \\
\hline $\mathrm{T} 2$ & 568 & 285 & 283 & & \\
\hline $\mathrm{T} 3$ & 126 & 48 & 78 & & \\
\hline $\mathrm{T} 4$ & 35 & 17 & 18 & & \\
\hline N Stage & & & & 2.431 & 0.488 \\
\hline No & 486 & 234 & 252 & & \\
\hline N1 & 330 & 168 & 162 & & \\
\hline $\mathrm{N} 2$ & 103 & 58 & 45 & & \\
\hline N3 & 71 & 35 & 36 & & \\
\hline M Stage & & & & 1.016 & 0.3134 \\
\hline$M x-0$ & 974 & 489 & 485 & & \\
\hline M1 & 16 & 6 & 10 & & \\
\hline TNM Stage & & & & 2.276 & 0.517 \\
\hline $\mathrm{x}-\mathrm{I}$ & 191 & 100 & 91 & & \\
\hline II & 560 & 276 & 284 & & \\
\hline III & 224 & 114 & 110 & & \\
\hline IV & 15 & 5 & 10 & & \\
\hline ER & & & & 5.765 & $0.0164^{*}$ \\
\hline Negative & 232 & 100 & 132 & & \\
\hline Positive & 758 & 395 & 363 & & \\
\hline PR & & & & 3.84 & 0.05 \\
\hline Negative & 327 & 149 & 178 & & \\
\hline Positive & 663 & 346 & 317 & & \\
\hline Her-2 & & & & 0.1181 & 0.7311 \\
\hline Negative & 828 & 412 & 416 & & \\
\hline Positive & 162 & 83 & 79 & & \\
\hline
\end{tabular}

$4 \mathrm{BC}$, breast cancer; TCGA, The Cancer Genome Atlas; ER, estrogen receptor; PR,

5 progesterone receptor; Her-2, human epidermal growth factor receptor-2. ${ }^{*} p<0.05$

6 indicates statistical significance. 